\title{
Differential expression of genes related to levels of mucosal cell proliferation among multiple rat strains by using oligonucleotide microsarays
}

\author{
S. Yamashita, Y. Bnomoto, T. Ohta, M. Ohki, T. Sugimura, T. Ushijima
}

Mammalian Genome, Vol. 14, No. 12, December 2003, pp. 845-852

(DOI: 10.1007/s00335-003-2299-3)

Figure 1 in the above-mentioned paper was inadvertently published in black and white. Below is the correct color version of Figure 1.

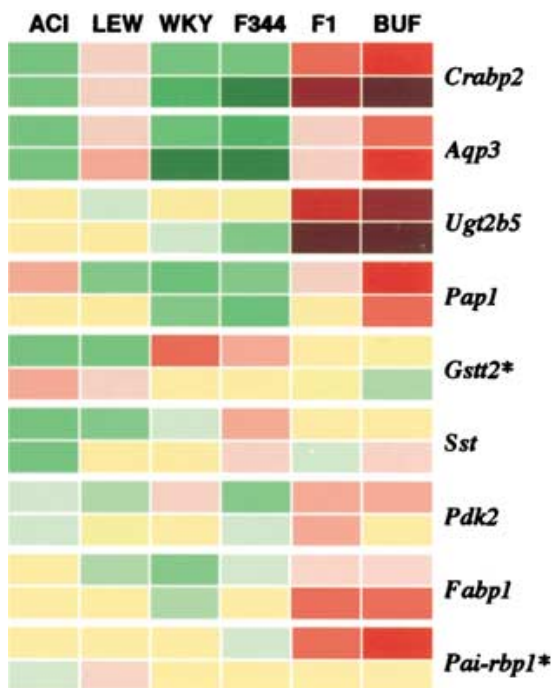

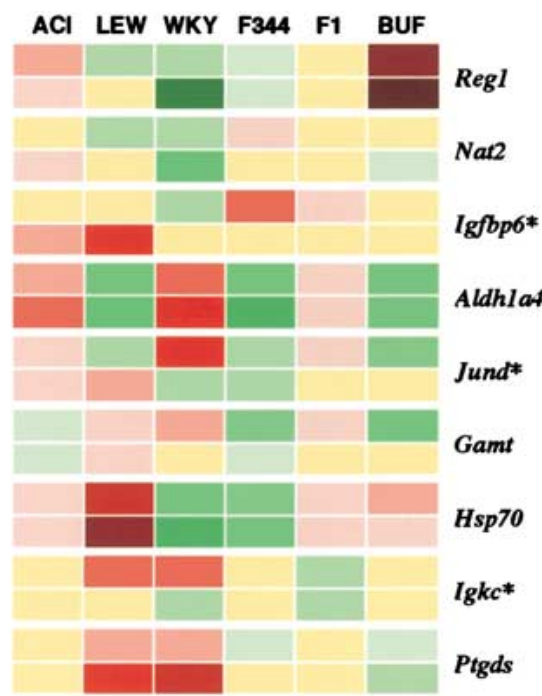

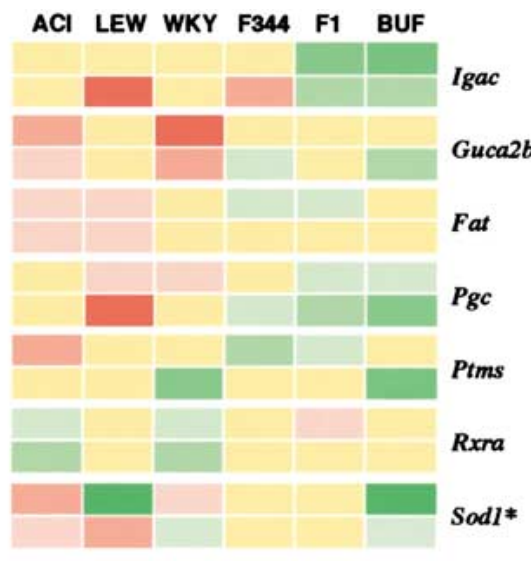

Fold change (V8. medlan of six strains)

$\begin{array}{llllllllllllll}-11.3 & -8.00 & -5.64 & -4.00 & -2.83 & -2.00 & -1.41 & 1.41 & 2.00 & 2.83 & 4.00 & 6.64 & 8.00 & 11.3\end{array}$

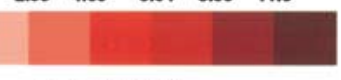

Up-regulated

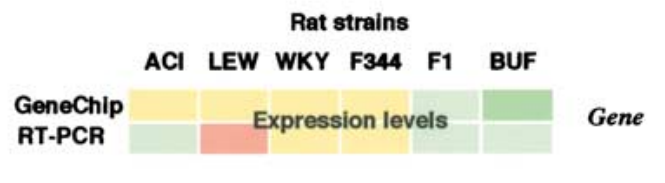

Fig. 1. Comparison of the results of the high-density oligonucleotide microarrays and the quantitative RTPCR. The expression profiles of 25 genes among six rat strains in the pylorus after MNNG treatment for 2 weeks are displayed. The upper six panels were the expression profiles analyzed by high-density oligonucleotide microarrays, and the lower six panels were the expression profiles analyzed by quantitative RT-PCR. The fold changes vs. median of six strains are presented in the graduated color patterns. Red, overexpression; green, under-expression; yellow, unchanged expression. ${ }^{\star}$ Discrepancies between the two analyses were observed in the six genres. 